\title{
论文
}

\section{柴达木盆地盐类沉积物中类脂物的分布特征及 天体生物学意义}

程子烨 ${ }^{1}$, 肖龙 ${ }^{2 *}$, 王红梅 ${ }^{3}$, 黄婷 $^{4}$

1. 广东财经大学地理与旅游学院, 广州 510320;

2. 中国地质大学(武汉)地质过程与矿产资源国家重点实验室行星科学研究所, 武汉 430074;

3. 中国地质大学(武汉)生物地质与环境地质国家重点实验室, 武汉 430074;

4. 澳门科技大学月球与行星科学国家重点实验室, 澳门 999078

* 通讯作者, E-mail: longxiao@cug.edu.cn

收稿日期: 2021-03-02; 收修改稿日期: 2021-06-02; 接受日期: 2021-07-01; 网络版发表日期: 2021-08-27 国家自然科学基金项目(批准号: 41903055)和广州市科技计划项目(编号: 202002030182)资助

摘要 地球盐类环境的类比研究是深入了解火星盐类沉积物中可能存在的生物分子的重要途径. 柴达木盆地是 中国开展火星类比研究的重要窗口, 文章对柴达木盆地大浪滩及察尔汗的盐类样品开展了类脂物分析, 并与前人 发表的不同时期和沉积环境的蒸发盐代表性样品进行对比. 结果表明, 柴达木盆地盐类样品中包含较为丰富的脂 肪酸化合物, 包括正构脂肪酸、不饱和脂肪酸、支链脂肪酸以及无环类异戊二烯烷酸, 也检测到甘油二烷基甘油 四醚化合物(GDGTs)和古菌醇(archaeol)化合物. 微生物来源的类脂物在蒸发盐中存在明显差异分布: 相对低盐的 盐类样品中, 脂肪酸的多样性更丰富、含量更高, GDGTs和archaeol化合物含量高于高盐样品, 当沉积物全部由盐 类矿物构成时, 类脂物的分布明显受到限制. 盐类矿物含量是造成类脂物差异分布的主控因素, archaeol化合物是 地球高盐沉积物中广泛分布的生物分子。本研究为限定和综合评价火星蒸发盐中可能存在的生命痕迹提供了一 种类比模式.

关键词 盐类沉积物, 类脂物, 天体生物学, 柴达木盆地, 火星

\section{1 引言}

天体生物学是研究生命在宇宙中的起源、演化和 分布, 分析太阳系以及系外宜居性的学科. 火星是太阳 系内最有希望发现地外生命的天体，对火星生命和宜 居环境的探索一直是行星科学领域的热点(Fairén等, 2010; Westall等, 2015). 围绕寻找火星生命及生命痕迹
的科学目标，过去几十年国际火星探测任务投放的火 星轨道器、着陆器和火星车开展了一系列对火星形貌 特征(Tanaka等, 2014; Kerber等, 2017)、水体(Hamilton 等，2018; Kronyak等，2019)和盐类矿物(Osterloo等, 2008; Grotzinger等, 2014; Vaniman等，2014)的探索. 探测结果显示火星表面分布有蒸发成因的盐类矿物, 包括硫酸盐、氯盐、高氯酸盐和碳酸盐等，它们是火 
星古湖泊干涸的产物(El-Maarry等，2013；Dang等， 2020). 这些古湖泊环境生成的盐类沉积物是探索火星 生命的重要目标, 而探测的重点是其中生命的痕迹, 包 括可能存在的生物成因的有机分子(Cockell等，2016; Eigenbrode等，2018). 由于目前还没有火星样品返回 地球，也没有人类能够到达火星进行相关实验，在地 球上进行类比研究依然是研究火星盐类沉积物中生命 的主要手段.

通过微生物培养的方法, 有学者在澳大利亚的Pilbara地区、西班牙Río Tinto地区和美国Death Valley区 域的盐类沉积物中分别检测出铁氧化菌、硫氧化菌和 耐盐微生物(Fernández-Remolar等，2005; Bowen等, 2008; Schubert等，2010)，从智利Atacama沙漠中上新 世蒸发盐中也识别出古菌和细菌(Rasuk等, 2014; Fernandez等, 2016). 这些研究区域是开展火星盐类环境 类比分析的典型区域，成功培养显示出微生物对这类 极端环境的适应能力. 然而, 地质体中 $95 \%$ 左右的微生 物都无法培养(柴丽红等, 2004), 其实体也较难保存, 微生物培养的手段限制了对蒸发盐中生命的系统认 识. 微生物脂类则相对稳定, 他们能够保存地质体中的 生物学信息. 脂类化合物被广泛应用于各种沉积物中 生命特征的分析(Georgiou和Deamer，2014; SánchezGarcía等, 2018; Klenner等, 2020)，也是火星盐类中最 有可能被保存下来的生命痕迹(Tan等, 2018; Williams 等，2021). 其中地质体中保存的磷脂脂肪酸的差异是 微生物分类的方法之一(Gharaibeh和Voorhees，1996), 盐类沉积物中较为丰富的异构脂肪酸表明样品所处的 地质时期细菌发育，不饱和脂肪酸一般被认为是真核 藻和细菌输入的标志(康晏等, 2006; Sánchez-García 等，2018). 以类异戊二烯、甘油为骨架的古菌细胞膜 脂甘油二烷基甘油四醚化合物(GDGTs)和古菌醇(archaeol)化合物与细菌脂肪酸不同，这种膜结构能适应 极端环境(Schouten等，2013)。这类化合物对高盐环境 响应异常敏感，也能示踪地质体中古菌的出现和群落 结构(Turich和Freeman, 2011; Wilhelm等, 2017). 然而, 对蒸发盐中类脂物的分布特征、不同地质时代及矿物 组成等构成的沉积单元中保存的类脂物的差异仍缺乏 系统研究，这极大地限制了人们通过类比研究探索火 星生命潜在的盐类介质和可能的目标生物分子.

持续的干旱、强紫外辐射和各种盐湖地貌使中国 柴达木盆地受到行星科学界的广泛关注，并在该盆地
系统开展了与火星地貌 $(X i a o$ 等, 2016; Anglés和Li, 2017; Dang等, 2018)、盐类矿物(Kong等, 2018; Wang 等, 2018)的类比研究, 为开展盐类沉积中的生物分子 分析奠定了基础. 本文选取柴达木盆地的蒸发盐沉积 物为研究对象, 探索这些盐类沉积物中水解后的总脂 肪酸、古菌GDGTs和archaeol化合物的分布特征, 并 与其他不同沉积特征的盐类沉积样品的结果对比, 从 而为限定和综合评价火星盐类环境中潜在的生命标记 物提供科学依据.

\section{2 样品及实验}

大浪滩盐湖位于柴达木盆地西北的阿尔金山下， 是柴达木盆地中上新世主要盐类沉积中心. DLT-P 沉 积剖面 $\left(38^{\circ} 31^{\prime} \mathrm{N}, 91^{\circ} 21^{\prime} \mathrm{E}\right.$ ) 位于大浪滩西北(图1a), 为前 人已整理开挖的剖面(马妮娜等，2011)。该剖面厚 $275 \mathrm{~cm}$, 是一套在湖水多次淡化-咸化交替中沉积的黏 土层和芒硝层互层明显的韵律沉积物(图1c). 铀系测 年结果显示剖面底部年龄为(195.1 \pm 10$) \mathrm{ka}$, 顶部年龄为 $(118.0 \pm 5) \mathrm{ka}$ (马妮娜等，2011). 该剖面不同层位沉积特 征差异明显, 是认识蒸发盐沉积中生物分子差异分布 的理想研究对象. 根据前人对DLT-P 3 剖面的描述和年 代标尺，我们在该剖面中选取了 11 个代表性样品开展 矿物学和类脂物的分析, 包括 6 个黏土层样品和 5 个芒 硝层样品. 在该剖面顶部也采集了 1 个盐壳样品. 同时, 在大浪滩小梁山还采集了 4 个表层样品开展矿物学和 类脂物的分析，包括 1 个明亮条带区域样品和 3 个暗色 条带区域样品(图1b). 察尔汗盐湖位于柴达木盆地中 东部，在晚更新世晚期(距今 3.2 万年)开始化学沉积, 距今约8000年至6000年的全新世中期温暖湿润气候期 结束盐湖沉积(朱允铸等, 1994; 陈宗颜等, 2011). CEH$\mathrm{P}_{3}$ 沉积剖面 $\left(36^{\circ} 55^{\prime} \mathrm{N}, 95^{\circ} 22^{\prime} \mathrm{E}\right)$ 位于察尔汗中部(图1a), 由于盐矿的开采剖面出露较好, 剖面厚 $660 \mathrm{~cm}$, 野外观 察到沉积物成分均一, 主要由石盐构成(图1d). 我们在 该剖面中选取了 2 个代表性样品开展矿物学和类脂物 的分析. 为避免采样过程、前处理、测试等环节的污 染, 野外样品采集时除去了表面10 30cm风化物质, 并 对出露的原生地层深挖. 采集的新鲜样品用锡箔纸严 密包裹，放入密封袋和干冰箱中，迅速运回实验室并 冷冻处理. 每个样品的样品量约 $500 \mathrm{~g}$, 以确保能够重 复实验. 


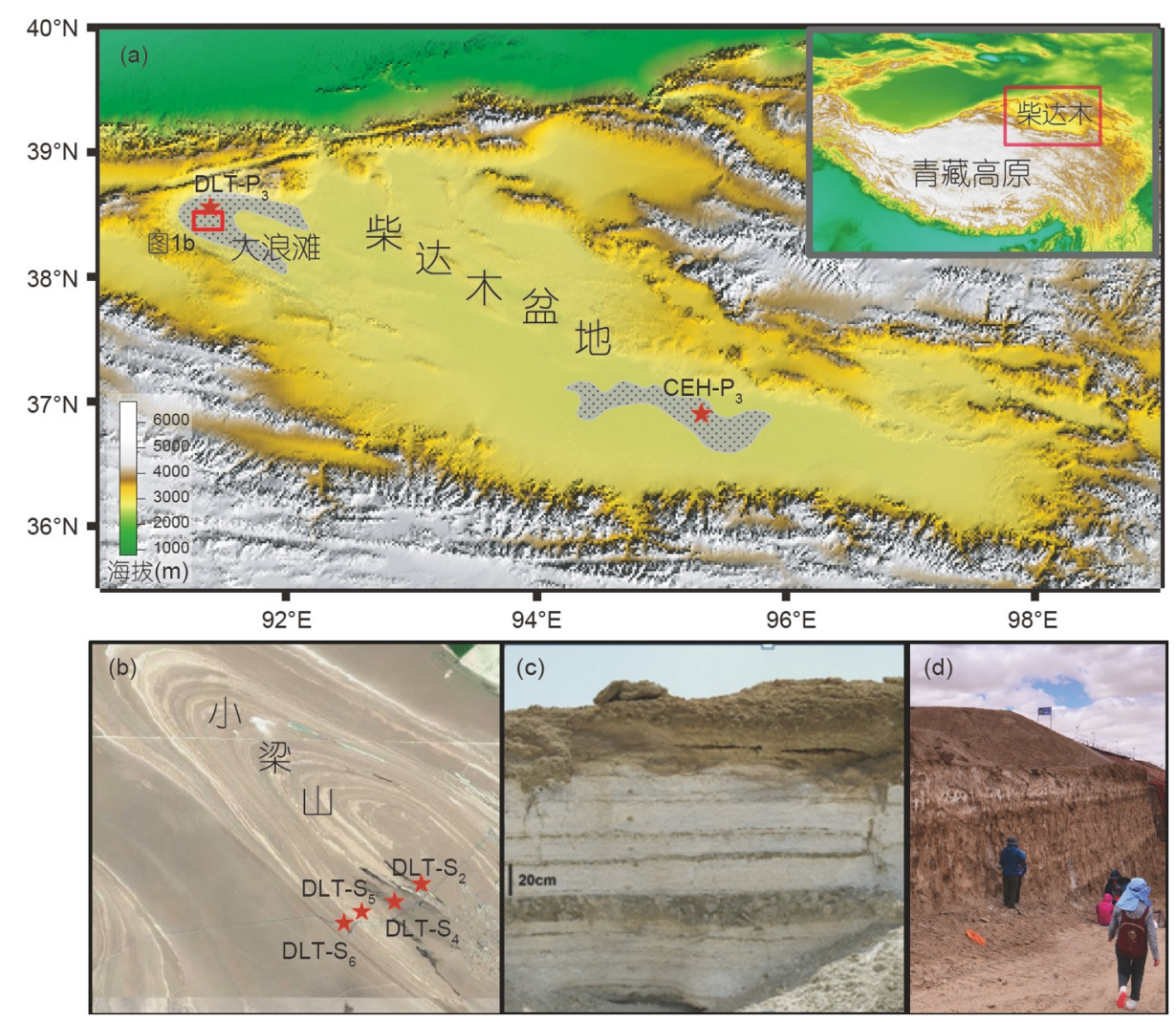

图 1 柴达木盆地大浪滩和察尔汗盐滩采样点分布图(a)、大浪滩表层样品分布(b)、大浪滩DLT-P 剖面(c)和察尔汗CEH-P $\mathbf{P}_{3}$ 剖面(d)

矿物学分析在中国地质大学(武汉)材料与化学学 院完成, 测试仪器名称为德国Bruker AXS D8 Advance $\mathrm{X}$ 射线衍射仪. 测试条件为 $\mathrm{Cu}$ 靶, $\mathrm{Ni}$ 滤波, LynxEye位阵 列探测器, 扫描范围 $5^{\circ} \sim 70^{\circ}$, 扫描时每步 $0.05 \mathrm{~s}$. 环境条 件温度为 $24^{\circ} \mathrm{C}$, 湿度为 $36 \%$. 矿物分析使用的软件为 $\mathrm{X}$ powder(Ver. 2010 PRO). 类脂物提取时, 首先将干燥后 的样品研磨至 100 目，称取样品约 $30 \sim 40 \mathrm{~g}$, 用二氯甲烷 $(\mathrm{DCM})$ 与甲醇 $(\mathrm{MeOH})$ 混合溶液DCM: $\mathrm{MeOH}(9: 1, v / v)$ $15 \mathrm{~mL}$ 提取类脂物. 加入混合溶液后, 样品超声 $15 \mathrm{~min}$, 每个样品重复超声抽提6次. 完成萃取后将萃取物用 旋转蒸发仪浓缩至 $3 \mathrm{~mL}$ 左右, 转移到 $5 \mathrm{~mL}$ 的细胞瓶内. 低温水浴锅上蒸干后㿝化, 配置 $1 \mathrm{~mol} \mathrm{~L}^{-1}$ 的 $\mathrm{KOH}$ 的甲 醇水溶液 (5\%的水)作为皇化试剂(配置 $30 \mathrm{~mL}, 1.5 \mathrm{~mL}$ 水, $2.2 \mathrm{~g}$ 的 $\mathrm{KOH}$ ). 㿝化后进行中性组分的萃取, 主要为 醇和酮, GDGTs存在于此组分中. 下层组分加入适量 配置好的盐酸至 $\mathrm{pH}<2$ 后进行酸性组分的萃取, 上机测 试前加入 $14 \%$ 的 $\mathrm{BF}_{3} / \mathrm{MeOH}$ 溶液进行甲酯化处理. 为防 止实验过程中的污染, 实验过程中的玻璃器血均在马
弗炉中经 $500^{\circ} \mathrm{C}$ 灼烧 $6 \mathrm{~h}$, 镊子等实验器材都经过DCM 淋洗后才使用. 每一批样品分析测试过程中都准备了 空白对照, 以确保实验过程没有污染. 分离后的酸性 组分经气相色谱-质谱(GC-MS)测试, 色谱条件: DB$5 \mathrm{MS}$ ，石英毛细管柱 $(60 \mathrm{~m} \times 0.25 \mathrm{~mm} \times 0.25 \mu \mathrm{m}), \mathrm{He}$ 为载 气. 脂肪酸检测限约为 $0.12 n g \mu \mathrm{L}^{-1}$. GDGTs经液相色 谱-质谱联用仪(LC-MS)测试, GDGTs化合物检测条件: $\mathrm{A}$ 流动相为正己烷, $\mathrm{B}$ 流动相为正己烷: 异丙醇 $(9: 1, v / v)$, 洗脱梯度为 $0 \sim 5 \mathrm{~min}, 90 \% \mathrm{~A}: 10 \% \mathrm{~B} ; 5 \sim 45 \mathrm{~min}, \mathrm{~A}$ 的比例 线性减至 $82 \%$, 接着冲洗色谱柱并回到 $100 \% \mathrm{~B}$, 该过程 流速保持 $0.2 \mathrm{~mL} \mathrm{~min}^{-1}$, 柱温箱恒温 $40^{\circ} \mathrm{C}$ (杨欢, 2010). 化合物离子化在 $\mathrm{APCI}$ 源中进行, $\mathrm{APCI} / \mathrm{MS}$ 条件为雾化 器压力 $60 \mathrm{psi}$, 雾化温度 $400^{\circ} \mathrm{C}$, 干燥气流速 $6 \mathrm{~L} \mathrm{~min}^{-1}$, 温 度 $200^{\circ} \mathrm{C}$, 毛细管电压 $3500 \mathrm{~V}$, 电晕电流 $5 \mu \mathrm{A}(\sim 3200 \mathrm{~V})$ (杨欢，2010). 对离子采用的是单离子扫描模式，扫描 质核比为1304、1302、1300、1298、1296、1292、 1050、1048、1046、1036、1034、1032、1022、 1020、1018、653和744(杨欢, 2010). GDGTs检测限约 
为 $10 \mathrm{pg} \mu \mathrm{L}^{-1}$.

\section{3 结果}

\section{1 矿物学特征}

DLT-P 3 剖面的矿物学分析结果与前人一致, 芒硝 层基本全部由芒硝矿物构成，黏土层以石亳、碳酸 盐、黏土和碎屑矿物为主(马妮娜等, 2011). 除了样品 DLT-P $\mathrm{P}_{3} \quad 200 \sim 215 \mathrm{~cm}$ 中包含 $16.5 \%$ 石膏和 $79.1 \%$ 无水芒 硝, 其他 4 个芒硝层样品中无水芒硝矿物含量均高于 97\%. 大浪滩表层样品和察尔汗剖面样品中矿物的X 射线粉晶衍射图谱见图2. 通过对柴达木盆地样品进 行X射线粉晶衍射分析, 发现大浪滩 4 个表层样品的矿 物组成存在明显差异. 其中DLT- $\mathrm{S}_{2}$ 的主要矿物组成为 石盐 $51.3 \%$ 、无水芒硝 $45.5 \%$ 和无定形矿物 $3.2 \%$; DLT$\mathrm{S}_{4}$ 的主要矿物组成为石盐 $79.0 \%$ 、石膏 $18.5 \%$ 和无定

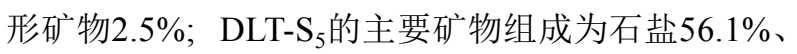
石膏 $16.7 \%$ 、微斜长石 $23.5 \%$ 和无定形矿物 $3.7 \%$; DLT$\mathrm{S}_{6}$ 的主要矿物组成为石盐 $98.1 \%$ 和无定形矿物 $1.9 \%$. $\mathrm{CEH}-\mathrm{P}_{3}$ 剖面2个层位的样品由石盐矿物构成，不同层 位矿物组成一致, 石盐矿物含量均高于 $98 \%$, 这也与野 外观察相符.

\section{2 脂肪酸的分布特征}

柴达木盆地DLT-P 3 剖面样品中包含较为丰富的脂 肪酸化合物，包括正构脂肪酸、不饱和脂肪酸、甲基 支链(异构和反异构)脂肪酸以及以植烷酸 $(\mathrm{Ph}: 0)$ 为主 的无环类异戊二烯烷酸(图3), 但DLT-P 3 剖面不同层位 的脂肪酸含量及分布特征差异显著. 在所分析的 11 个 样品中, 碳链长度大于 20 的植物来源的脂肪酸主要出 现在黏土层中, 总含量为 $24.96 \sim 449.22 \mathrm{ng} \mathrm{g}^{-1}$ 沉积物干 重. 不饱和脂肪酸 $n \mathrm{C}_{18: 1}$ 在芒硝层及黏土层中均有出

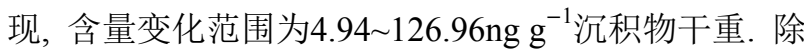
了样品DLT- $\mathrm{P}_{3} 154 \sim 156 \mathrm{~cm}$ 中未检测到甲基支链脂肪酸 外, 其他 5 个黏土层中都检测到了一定浓度的异构和反 异构脂肪酸(包括 $\mathrm{i} 14: 0 、 \mathrm{a} 14: 0 、 \mathrm{i} 15: 0 、 \mathrm{a} 15: 0 、 \mathrm{i} 16: 0$ 、 i1 $7: 0$ 和a17:0), 总含量为 $11.74 \sim 709.64 \mathrm{ng} \mathrm{g}^{-1}$ 沉积物干 重，而5个芒硝层位样品中均未检测到甲基支链脂肪 酸(图3, 图4). 检测到的植烷酸也主要分布在黏土层 中, 含量变化范围为3.35 1405.19ng g ${ }^{-1}$ 沉积物干重(图 $3)$. 该剖面顶部的盐壳样品中未检测到脂肪酸化合物.
表层样品DLT- $\mathrm{S}_{5}$ 中检测到了 $n \mathrm{C}_{18: 1}$ 化合物, 含量为 $3.23 \mathrm{ng} \mathrm{g}^{-1}$ 沉积物干重, 其他 3 个大浪滩表层样品及 $\mathrm{CEH}-\mathrm{P}_{3}$ 剖面样品中未检测到不饱和脂肪酸、支链脂 肪酸以及植烷酸(图3). 不同样品中支链脂肪酸、植烷 酸的差异分布与沉积物中盐类矿物总含量有关, 当样 品的盐类矿物总含量 $>95 \%$ 时, 它们的分布明显受到限 制(图3). 虽然样品间盐类矿物类型不同, 例如DLT-P 剖面高盐层基本全为无水芒硝, CEH-P 3 剖面高盐层由 石盐矿物构成, 但这些样品中支链脂肪酸、植烷酸的 缺失现象并无差异.

\subsection{GDGTs和archaeol化合物的分布特征}

DLT-P 3 剖面样品中检测到GDGTs和archaeol化合 物, 每个样品中 archaeol含量明显高于其他化合物, 古 菌合成的GDGT-0次之(网络版附表1, http://earthen.scichina.com). 其他古菌来源的iGDGTs化合物仅出现在3 个黏土层样品中. 细菌合成的bGDGTs含量较低, 总含 量为 $0.05 \sim 4.47 \mathrm{ng} \mathrm{g}^{-1}$ 沉积物干重, 仅在 4 个黏土层中有 明显分布(图4, 网络版附表1). DLT-P 剖面样品中archaeol和GDGT-0含量在不同层位差异明显, 除了样品 DLT- $P_{3} 21 \sim 47 \mathrm{~cm}$, 其他所有黏土层中 archaeol和GDGT0 含量明显高于芒硝层(图4). 该剖面顶部的盐壳样品 中只检测到archaeol和GDGT-0, 浓度分别为 $3.00 \mathrm{ng} \mathrm{g}^{-1}$ 沉积物干重、 $0.01 \mathrm{ng} \mathrm{g}^{-1}$ 沉积物干重. 表层样品DLT-S 5 中检测到了 archaeol、GDGT-0及细菌合成的bGDGTs, 含量分别为 $829.88 \mathrm{ng} \mathrm{g}^{-1}$ 沉积物干重、 $2.32 \mathrm{ng} \mathrm{g}^{-1}$ 沉积 物干重、0.96 $\mathrm{ng} \mathrm{g}^{-1}$ 沉积物干重. 其他 3 个大浪滩表层 样品及CEH-P 剖面样品中未检测到GDGTs化合物, archaeol化合物在这些样品中均有出现, 但archaeol浓度 明显低于DLT- $S_{5}$, 含量变化范围为11.64 263.87 $\mathrm{ng} \mathrm{g}^{-1}$ 沉积物干重. 同样, 当样品中盐类矿物的总含量 $>95 \%$ 时，不管盐类矿物的类型如何, GDGTs化合物的分布 也受到限制.

\section{4 讨论}

\section{1 类脂物生物来源}

DLT- P $_{3}$ 剖面顶部的盐壳样品中没有检测到脂肪酸 化合物, 只检测到低浓度的archaeol和GDGT-0, 说明剖 面中检测到的丰富的脂肪酸化合物、 archaeol和 GDGTs化合物不大可能来自后期输入. 同时, 如果存 

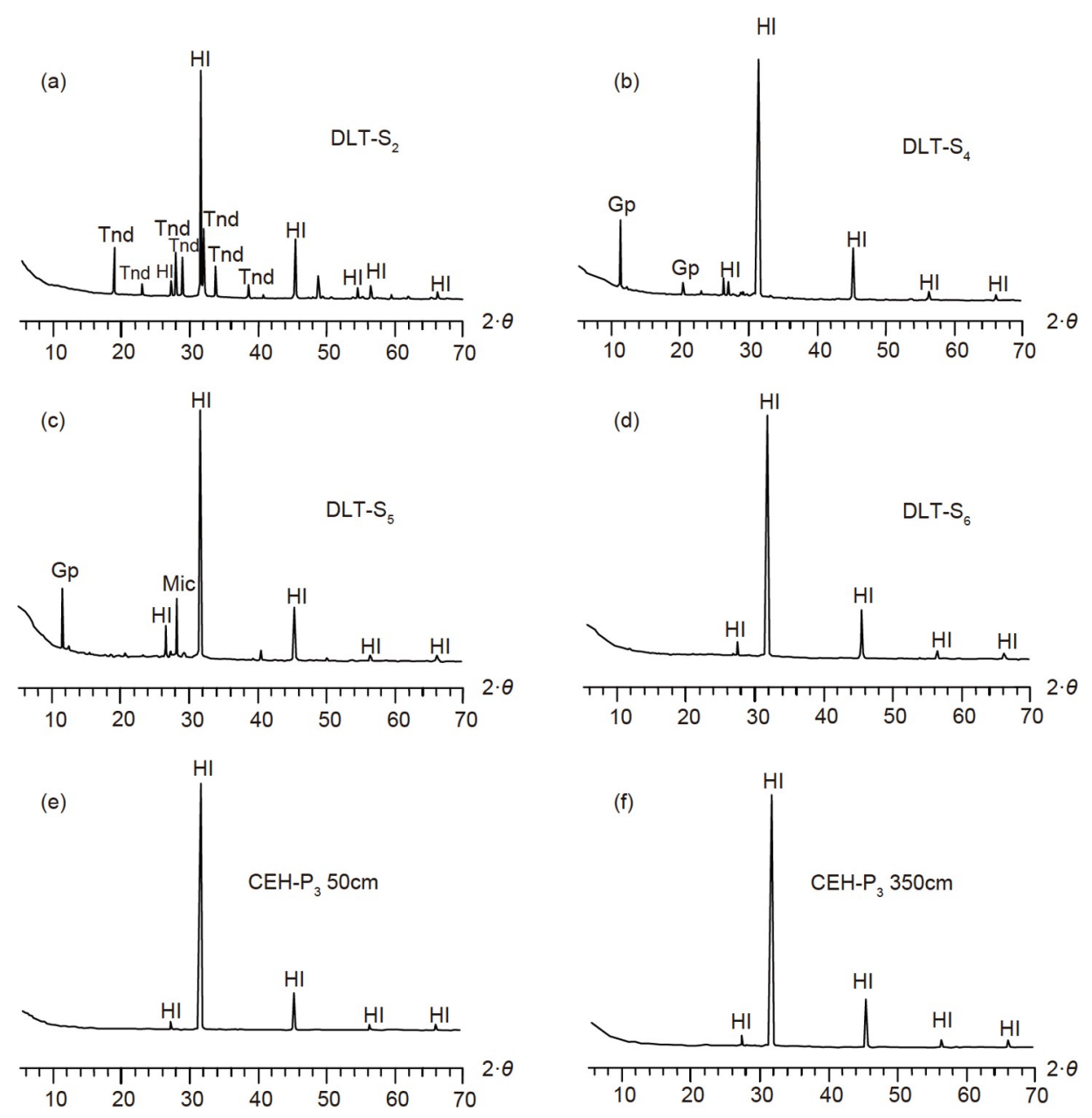

图 2 柴达木盆地盐类沉积物样品粉晶X射线衍射图谱

(a) (d) 大浪滩表层沉积物样品; (e) (f) 察尔汗剖面沉积物样品. Tnd, 无水芒硝; Hl, 石盐; Gp, 石言; Mic, 微斜长石

在明显的后期输入, 剖面各芒硝层中应该出现一些黏 土层特有的类脂分子. 因此，DLT-P 剖面不同层位中 检测到的类脂物代表的是历史沉积环境的有机物组 成. 沉积物中脂肪酸有一定的生物分类学意义. 碳链长 度大于 20 的脂肪酸一般来自于植物叶蜡等成分(Xie等, 2003), 柴达木盐类样品中碳链长度大于 20 的脂肪酸基 本出现在DLT-P 3 黏土层中, 相对含量较低. 不饱和脂肪 酸在其他高盐沉积物中也检测到，被认为来自真核藻 和细菌的贡献(Gong和Hollander, 1997; 康晏等, 2006), DLT- $\mathrm{S}_{5}$ 样品和DLT- $\mathrm{P}_{3}$ 剖面黏土层位中 $n \mathrm{C}_{18: 1}$ 不饱和脂 肪酸可能主要来自细菌、真核藻等低等生物。与芒硝 层相比，DLT-P 3 剖面黏土层位中的甲基支链脂肪酸较 为丰富(图4), 表明样品所处地层细菌发育(Kaneda, 1991; Rütters等, 2002; 杨欢等,2014). 以植烷酸为主的
无环类异戊二烯烷酸同样在中国江汉盆地等其他盐类 沉积物中被检测到, 并认为是来自古菌的贡献, 尤其是 产甲烷古菌与嗜盐古菌(Schouten等, 1997; 康晏等, 2006), 它们可能是DLT-P 3 黏土层中无环类异戊二烯烷 酸的生物来源.

产甲烷古菌在湖泊环境中广泛分布, 是盐类沉积 物中GDGT-0 最可能的生物来源(Blaga等，2009; 李婧 婧, 2014). 在分析柴达木盆地茶卡盐湖沉积物中古菌 群落时, 也发现产甲烷古菌是沉积物中主要古菌类型 (Jiang等，2006). 盐类样品中GDGT-0 明显高于其他 GDGTs化合物, 因此柴达木盆地DLT-P 3 剖面及表层样 品DLT-S S $_{5}$ 检测到的GDGT-0主要来自产甲烷古菌的 贡献. Archaeol化合物生物来源较为广泛, 盐湖环境中 的嗜盐古菌和产甲烷古菌都能合成这类古菌二醚化合 


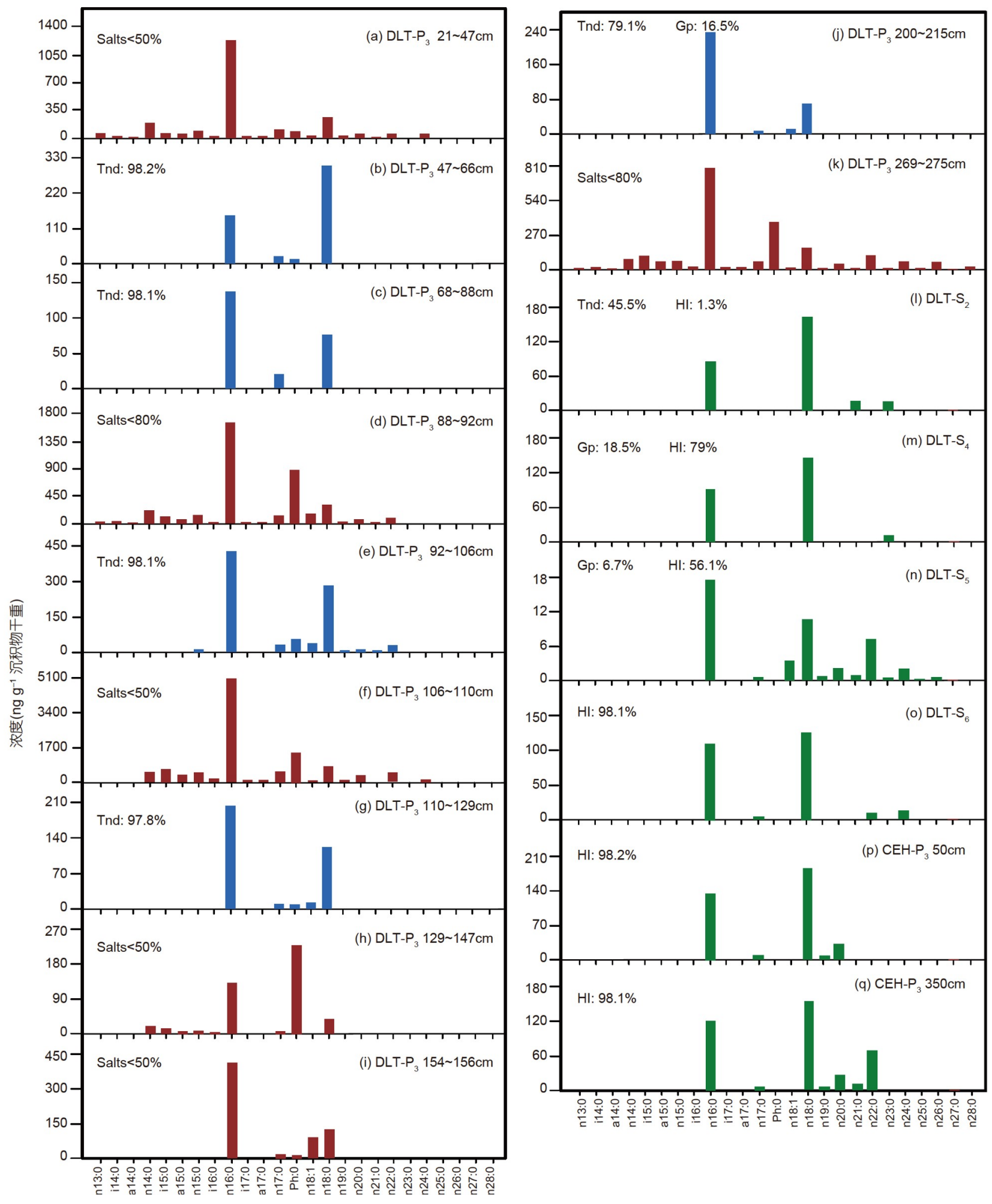

图 3 柴达木盆地样品的脂肪酸分布特征

红色代表DLT-P P $_{3}$ 剖面黏土层; 蓝色代表DLT-P 3 剖面芒硝层, 盐类矿物总含量均 $>95 \%$; 绿色代表大浪滩表层沉积物及CEH-P 3 剖面样品, 其中 DLT-S 盐类矿物总含量为 $72.8 \%$, 其他样品均 $>96 \%$. Tnd, 无水芒硝; $\mathrm{Hl}$, 石盐; Gp, 石膏; Sallts, 盐类矿物总含量 


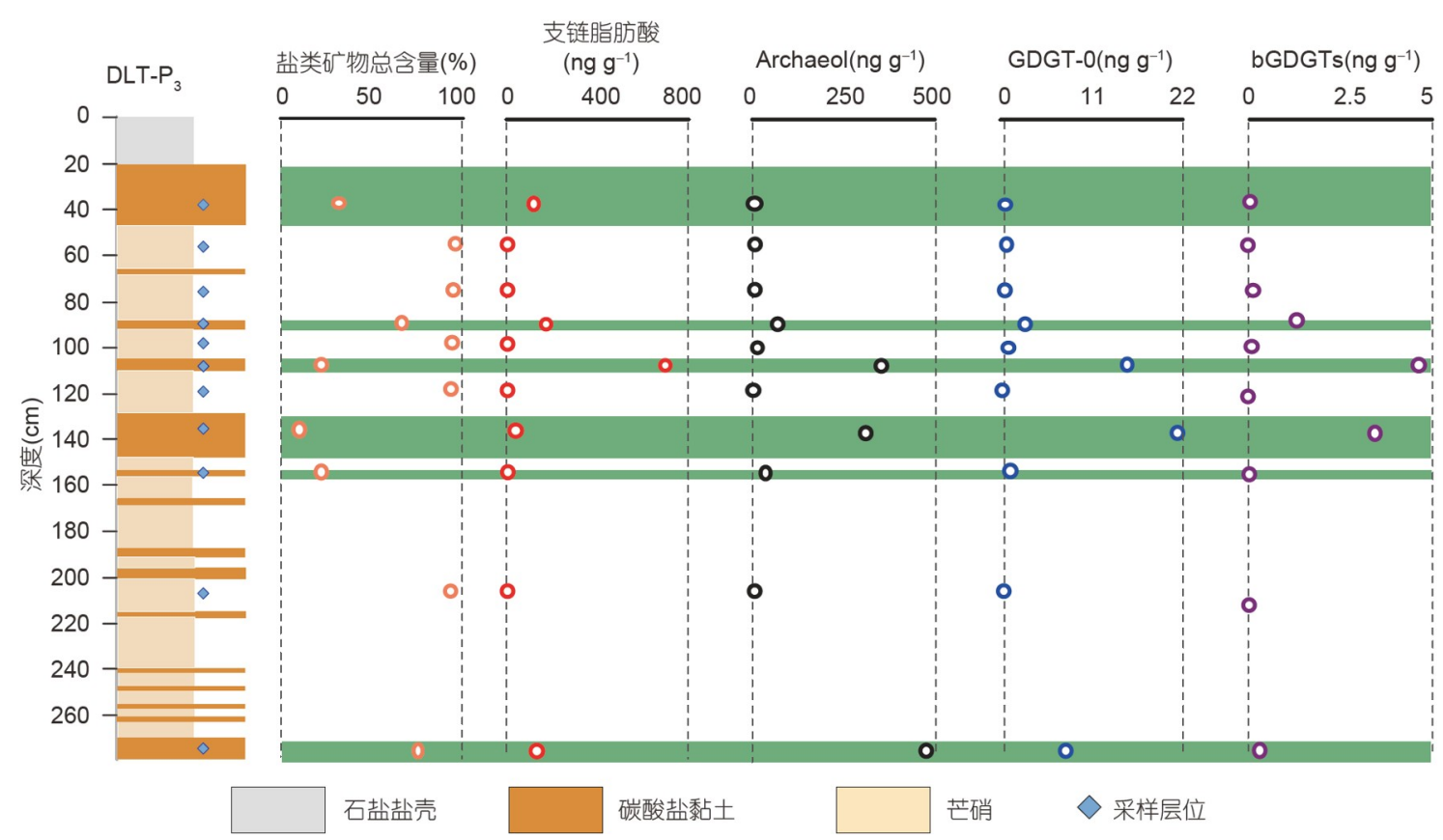

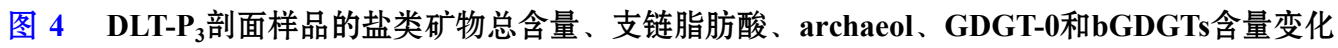

物(Pancost等, 2001; Niemann和Elvert, 2008). 在我们的 样品中，由于archaeol含量明显高于其他古菌来源的 iGDGT化合物, 因此嗜盐古菌应该是沉积物中 archaeol 化合物的主要贡献者. 这种古菌生物来源也与前面产 甲烷古菌与嗜盐古菌贡献的无环类异戊二烯烷酸的出 现一致.

\section{2 盐类环境生命保存特征对比分析}

微生物来源的支链脂肪酸化合物在DLT-P 3 芒硝层 和黏土层中存在非常明显的含量和组成差异．相比芒 硝层(图5a), 黏土层中脂肪酸分子的含量更高、类型 更丰富(图5c). 这种生物分子的分布特征在大浪滩表 层样品及 $\mathrm{CEH}-\mathrm{P}_{3}$ 剖面样品中也同样存在. 与含有 $23.5 \%$ 碎屑矿物的样品DLT- $\mathrm{S}_{5}$ 相比, 其他高盐样品中 脂肪酸的多样性明显偏低. 我们之前分析过以石膏为 主要盐类矿物的大浪滩剖面DLT-P 和DLT-P $_{2}$, 发现两 个剖面中黏土单元的支链脂肪酸含量和多样性明显高 于高盐单元(Cheng等, 2017), 支链脂肪酸、不饱和脂 肪酸和碳链长度大于 20 的脂肪酸主要出现在黏土单元 (图5e). 然而，这两个剖面的沉积特征相对简单，每个 剖面仅包含蒸发盐沉积单元和黏土沉积单元，沉积物 中盐类矿物组成也比较单一，限制了我们系统认识盐
类物质中生物分子的分布规律及差异分布的主控因

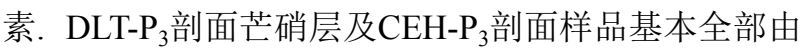

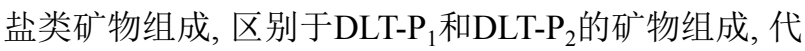
表了一类更为极端的盐类环境. 这类高盐环境明显限 制细菌等微生物的生长，甚至没有检测到细菌来源的 支链脂肪酸, 而黏土层中细菌、古菌和可能的植物来 源说明相对低盐的环境支持更多样化的生态系统. 同 时, 结合样品的矿物学分析, 发现脂肪酸的差异分布 主要受盐类矿物含量控制. 盐类矿物含量极高时, 支 链脂肪酸、植烷酸的分布明显受限，而这种差异分布 与盐类矿物类型无关.

Atacama沙漠是地球上最接近火星的自然环境之 一，自2Ma起的极端干旱环境使得该地区大量干盐湖 得以形成, 盐类沉积物中生命特征的研究早已开展. 通过分析Atacama沙漠一个 $2.5 \mathrm{~m}$ 深剖面类脂物的分布, 发现黏土层和蒸发盐层中脂肪酸、GDGTs分布和丰 度均存在明显差异(Wilhelm等，2017)。高盐的蒸发盐 层中支链脂肪酸含量低于黏土层位，脂肪酸的多样性 也明显少于黏土层位(图5b、5d)，与柴达木盆地剖面 样品的脂肪酸分布较为类似. 另一方面, 柴达木盆地 DLT-P 3 剖面黏土层中脂肪酸分布特征与Atacama沙漠 样品也存在明显差异. 如图5d所示, Atacama沙漠Yun- 


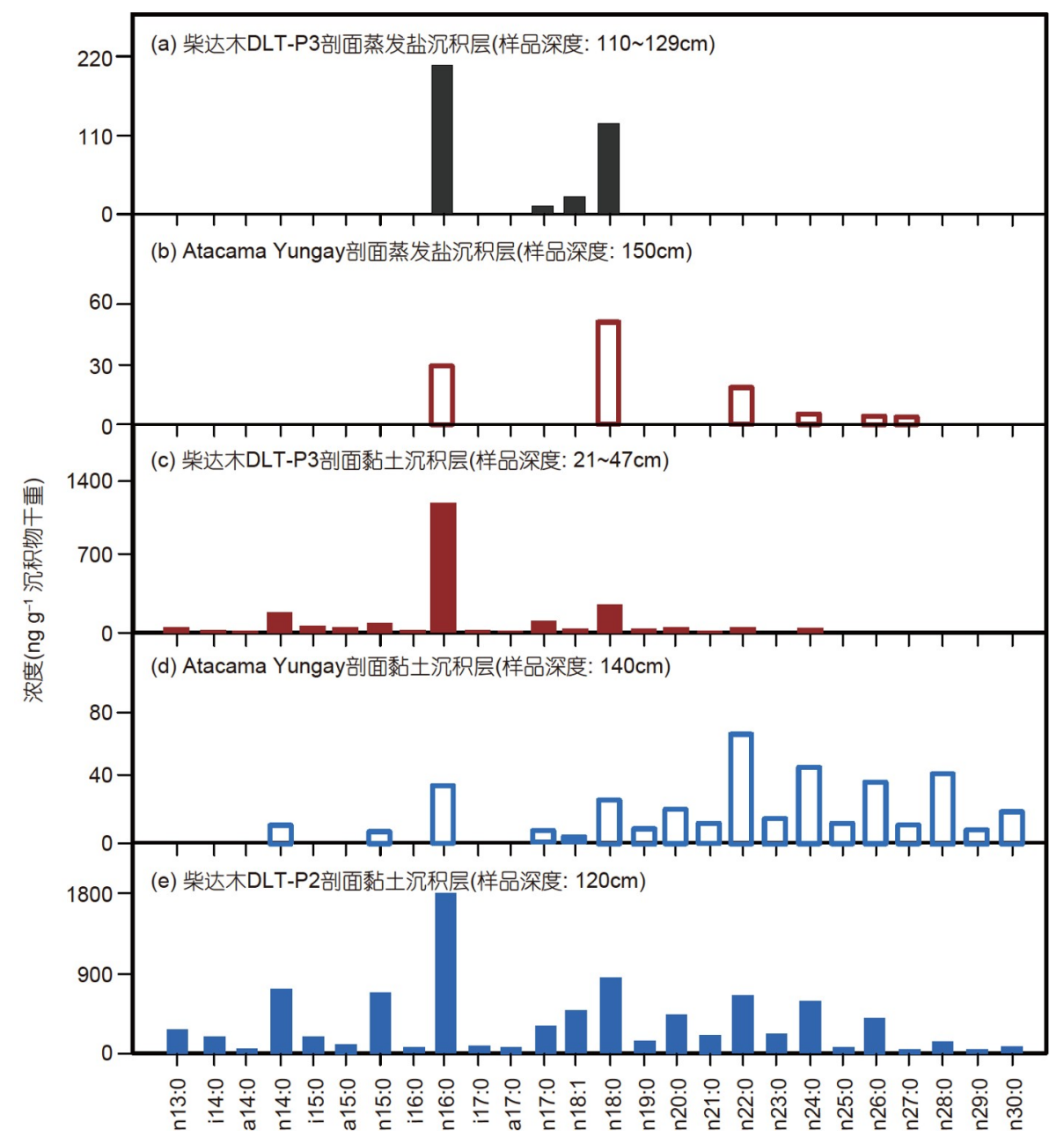

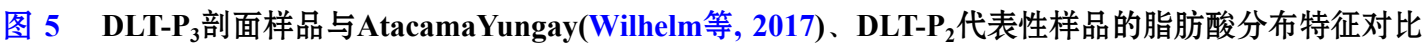

gay剖面黏土层中高碳数脂肪酸含量均较高, 甚至占主 导地位, 主峰碳处于 $\mathrm{C}_{22} \sim \mathrm{C}_{28}$, 说明了Atacama沙漠黏土 层沉积时的陆源植物输入. 这种现象也与野外观察一 致, 我们在盐类沉积物采样过程中未见植物痕迹, 而 Atacama沙漠黏土层中可见纤维状植物碎片 (Wilhelm 等, 2017). 这种对比也进一步说明了柴达木盆地盐类 环境的极端性, 例如比Atacama沙漠更高的太阳辐射强 度(Georgiou等, 2015).

前人对高盐的海洋、盐湖沉积物GDGTs化合物 的研究结果表明, 高盐环境制约微生物的生长, 导致这 类环境沉积物中GDGTs化合物含量较低甚至缺失，但 盐类矿物组成对这类化合物分布的影响还需深入调 查. Stiehl等(2005)在死海沉积物中并未发现任何 GDGTs, Turich和Freeman(2011)分析全球范围内海洋
高盐卤水沉积物中GDGTs化合物和archaeol分布时只 检测到archaeol和GDGT-0. Jones(2011)分析澳大利亚 中更新世的高盐沉积物中GDGTs分布，结果只有 $20 \%$ 的高盐样品检测到GDGT-0. 李婧婧(2014)对茶卡盐湖 沉积物分析发现高盐沉积物GDGTs化合物的分布也 以高含量的GDGT-0化合物为主. 前文提到的Atacama 沙漠的 $2.5 \mathrm{~m}$ 深的盐类剖面中, 同样发现古菌来源的 GDGT-0化合物和细菌合成的bGDGTs出现在底部的 黏土层中, 却在顶部的石亳层中没有检测到(Wilhelm 等, 2017). 对柴达木盆地盐类沉积物中GDGTs化合物 和archaeol的分析结果确认了这一认识. 柴达木盆地沉 积物样品中 GDGT-0 以及较低含量细菌来源的 bGDGTs化合物主要出现在DLT-P 3 剖面黏土层中, 而 其他古菌来源的iGDGTs化合物含量极低, 以至于大部 
分样品中该类化合物都低于检测值. 结合柴达木盆地 样品的矿物组成分析, 进一步明确了盐类矿物含量控 制GDGTs化合物的分布, 当盐类矿物含量极高时, 古 菌来源的类脂物分布也受到限制. 此外, 我们还认识 到archaeol化合物在盐类沉积物中广泛分布.

\section{3 天体生物学意义}

地球极端环境生物分子研究能够为探索火星生命 提供一种模式体，这也是天体生物学近年来研究的热 点问题. 火星古湖泊盐类环境一直是寻找火星生命(或 痕迹)的重要目标. 除了广泛分布在火星表面的不同盐 类含量的蒸发盐(郑绵平等, 2014), 着陆器“机遇号”返 回的数据还显示火星梅里迪亚尼平原鹰陨击坑内出露 厚约 $7 \mathrm{~m}$ 的由碎屑和硫酸盐构成的沉积剖面, 记录了一 段时期的蒸发干旱事件(Grotzinger等, 2005), 与大浪滩 剖面沉积特征极为相似. Mars 2020探测器已经着陆在 火星Jezero撞击坑内, 在着陆点附近的湖相沉积物、包 括黏土物质和可能存在的盐类物质中寻找生命的证据 是这次火星探测的重要使命之一(Tarnas等, 2019; Horgan等, 2020). 与柴达木盆地相比，火星环境具有更温 和的成岩作用及更低的温度，这对于生物分子的保存 更有利(Fernández-Remolar等, 2013).

柴达木盆地盐类沉积物中类脂分子的分布特征能 为今后限定和有目的地寻找火星盐类环境可能存在的 生命痕迹提供重要参考. 结合柴达木盆地不同矿物组 成及沉积特征的蒸发盐剖面和表层盐类样品, 并通过 与其他盐类环境沉积物中类脂物保存特征对比，我们 发现微生物来源的类脂物在盐类沉积物中存在明显的 分布规律. 已有的火星探测能够评估火星沉积物中盐 类含量(Clark等, 2005; Karunatillake等, 2007), 由于地 球盐类矿物含量是控制沉积物中类脂物分布的主要因 素，因此火星不同盐类含量的沉积物中可能保存的生 物分子应该存在差异.

火星地表的电离辐射每年高达 $0.54 \sim 0.85 \mathrm{Gyr}$ (Dartnell等, 2007), 对保存有机分子极为不利. 前人研究表 明, 每经过 $300 \mathrm{Myr}$, 火星电离辐射会使表层 $5 \mathrm{~cm}$ 沉积物 中生物大分子含量降低 1000 倍，这些生物大分子包括 GDGTs化合物和archaeol(Pavlov等，2012). 地球盐类 沉积物中GDGTs化合物含量较低, 我们的样品中 GDGTs化合物总含量最高值为 $23.29 \mathrm{ng} \mathrm{g}^{-1}$. 如果这些 化合物经过数十亿年的火星地表电离辐射, 它们很难
被仪器检测到. 因此，火星地下的盐类沉积物才是寻 找火星生命的潜在目标. 好奇号火星车最大钻探深度 为 $6 \mathrm{~cm}$, 而ExoMars计划设计的最大钻探深度为 $2 \mathrm{~m}$, 满 足有机信号被检测到的条件. 海盗号和好奇号都曾携 带GC-MS, 也满足检测archaeol等化合物的仪器条件. Archaeol化合物在地球高盐环境中广泛分布，火星地 下盐类沉积物中 archaeol化合物是值得关注的潜在生 命信号.

\section{5 结论}

本文对柴达木盆地大浪滩表层沉积物、DLT-P 3 剖 面和察尔汗 CEH-P 3 剖面盐类沉积物样品开展了类脂 物分布的初步分析，并与前人发表的不同沉积环境或 沉积特征盐类中类脂物分布进行了对比, 得到的主要 认识如下:

（1）大浪滩 4 个表层样品的矿物组成存在明显差 异，DLT-P 剖面为黏土层和芒硝层互层明显的韵律沉 积物, 察尔汗 $\mathrm{CEH}-\mathrm{P}_{3}$ 剖面则为矿物组成单一的石盐沉 积物. 类脂物在这些沉积物中存在差异分布, 当盐类矿 物含量极高时, 类脂物分布受到限制. 这种差异分布与 沉积物样品中盐类矿物总含量相关, 而与盐类矿物的 类型无关.

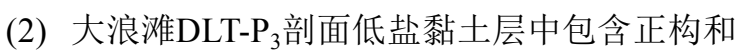
不饱和脂肪酸，无环类异戊二烯烷酸和甲基支链脂肪 酸也被检测到. 大浪滩表层样品DLT-S 5 中也检测到了 不饱和脂肪酸. 这种分布特征表明这些沉积物样品中 微生物发育. DLT-P 剖面芒硝层、大浪滩 3 个高盐表 层样品与 CEH-P 3 剖面样品中未检测到明显的支链脂 肪酸, 表明高盐环境会限制细菌微生物的生长.

(3) 大浪滩DLT-P 剖面样品中检测到GDGTs和archaeol化合物, 其中 archaeol含量最高, 古菌合成的 GDGT-0次之, 黏土层中 archaeol和GDGT-0 含量明显高 于芒硝层. 大浪滩表层样品DLT- $\mathrm{S}_{5}$ 中也检测到了 archaeol和较低含量的GDGT-0化合物，其他 3 个高盐表 层样品及CEH-P 3 剖面样品中检测到了较低含量的archaeol化合物, 但未检测到GDGTs化合物. 这种现象表 明盐类矿物含量同样控制GDGTs化合物的含量变化. 产甲烷古菌与嗜盐古菌分别是盐类样品中GDGT-0 和 archaeol化合物的主要贡献者.

最后，通过与盐类环境生命保存其他研究成果的 
对比分析，明确了盐类沉积物中类脂物的分布规律、 差异分布的主控因素及高盐沉积物中值得关注的生物 分子. 本文的研究结果为限定和综合评价火星蒸发盐 中可能存在的生命痕迹提供了一种类比模式.

致谢感谢中国地质大学(武汉)王江及赵健楠博士在采 样中的帮助.

\section{参考文献}

柴丽红, 崔晓龙, 彭谦, 徐丽华, 姜成林. 2004. 青海两盐湖细菌多样 性研究. 微生物学报, 44: 271-275

陈宗颜, 陈克龙, 罗正霞. 2011. 察尔汗地区130ka B.P. 以来湖相沉积 物颜色记录的气候变化探讨. 盐湖研究, 19: 1-7, 14

康晏, 王万春, 张道伟, 任军虎. 2006. 柴达木盆地第四系脂肪酸生标 的检出及其地质意义. 沉积学报, 24: 456-460

李婧婧. 2014. 不同盐度湖泊微生物脂类分布特征及其环境意义. 博 士学位论文. 武汉: 中国地质大学. 1-123

马妮娜, 郑绵平, 马志邦, 陈文西, 孔凡晶, 施林峰. 2011. 柴达木盆地 大浪滩地区表层芒硝的形成时代及环境意义. 地质学报, 85: 433-444

杨欢. 2010. 中国土壤微生物类脂物对现代过程的响应及其古环境 意义. 硕士学位论文. 武汉: 中国地质大学. 1-66

杨欢, 丁伟华, 谢树成. 2014. 海南尖峰岭不同海拔土壤中微生物脂 肪酸和脂肪醇分布特征及对古海拔、古温度重建的启示. 中国 科学: 地球科学, 44: 1229-1243

郑绵平, 孔维刚, 陈文西, 孔凡晶, 张雪飞. 2014. 地球同火星蒸发岩 沉积的对比. 高校地质学报, 20: 169-176

朱允铸, 钟坚华, 李文生. 1994. 柴达木盆地新构造运动及盐湖发展 演化. 北京: 地质出版社. 79

Anglés A, Li Y L. 2017. Similar ring structures on Mars and Tibetan Plateau confirm recent tectonism on Martian Northern polar region. Int J Astrobiol, 16: 355-359

Blaga C I, Reichart G J, Heiri O, Sinninghe Damsté J S. 2009. Tetraether membrane lipid distributions in water-column particulate matter and sediments: A study of 47 European lakes along a northsouth transect. J Paleolimnol, 41: 523-540

Bowen B B, Benison K C, Oboh-Ikuenobe F E, Story S, Mormile M R. 2008. Active hematite concretion formation in modern acid saline lake sediments, Lake Brown, Western Australia. Earth Planet Sci Lett, 268: 52-63

Cheng Z Y, Xiao L, Wang H M, Yang H, Li J J, Huang T, Xu Y, Ma N N. 2017. Bacterial and archaeal lipids recovered from subsurface evaporites of Dalangtan Playa on the Tibetan Plateau and their astrobiological implications. Astrobiology, 17: 1112-1122
Clark B C, Morris R V, McLennan S M, Gellert R, Jolliff B, Knoll A H, Squyres S W, Lowenstein T K, Ming D W, Tosca N J, Yen A, Christensen P R, Gorevan S, Brückner J, Calvin W, Dreibus G, Farrand W, Klingelhoefer G, Waenke H, Zipfel J, Bell III J F, Grotzinger J, McSween H Y, Rieder R. 2005. Chemistry and mineralogy of outcrops at Meridiani Planum. Earth Planet Sci Lett, 240: 73-94

Cockell C S, Bush T, Bryce C, Direito S, Fox-Powell M, Harrison J P, Lammer H, Landenmark H, Martin-Torres J, Nicholson N, Noack L, O'Malley-James J, Payler S J, Rushby A, Samuels T, Schwendner P, Wadsworth J, Zorzano M P. 2016. Habitability: A review. Astrobiology, 16: 89-117

Dang Y N, Xiao L, Xu Y, Zhang F, Huang J, Wang J, Zhao J N, Komatsu G, Yue Z. 2018. The polygonal surface structures in the Dalangtan playa, QaidamBasin, NW China: Controlling factors for their formation and implications for analogous Martian landforms. J Geophys Res-Planets, 123: 1910-1933

Dang Y N, Zhang F, Zhao J N, Wang J, Xu Y, Huang T, Xiao L. 2020. Diverse polygonal patterned grounds in the Northern Eridania Basin, Mars: Possible origins and implications. J Geophys ResPlanets, 125: e06647

Dartnell L R, Desorgher L, Ward J M, Coates A J. 2007. Modelling the surface and subsurface martian radiation environment: Implications for astrobiology. Geophys Res Lett, 34: L02207

Eigenbrode J L, Summons R E, Steele A, Freissinet C, Millan M, Navarro-González R, Sutter B, McAdam A C, Franz H B, Glavin D P, Archer Jr P D, Mahaffy P R, Conrad P G, Hurowitz J A, Grotzinger J P, Gupta S, Ming D W, Sumner D Y, Szopa C, Malespin C, Buch A, Coll P. 2018. Organic matter preserved in 3billion-year-old mudstones at Gale crater, Mars. Science, 360: 1096-1101

El-Maarry M R, Pommerol A, Thomas N. 2013. Analysis of polygonal cracking patterns in chloride-bearing terrains on Mars: Indicators of ancient playa settings. J Geophys Res-Planets, 118: 2263-2278

Fairén A G, Davila A F, Lim D, Bramall N, Bonaccorsi R, Zavaleta J, Uceda E R, Stoker C, Wierzchos J, Dohm J M, Amils R, Andersen D, McKay C P. 2010. Astrobiology through the ages of Mars: The study of terrestrial analogues to understand the habitability of Mars. Astrobiology, 10: 821-843

Fernández-Remolar D C, Morris R V, Gruener J E, Amils R, Knoll A H. 2005. The Río Tinto Basin, Spain: Mineralogy, sedimentary geobiology, and implications for interpretation of outcrop rocks at Meridiani Planum, Mars. Earth Planet Sci Lett, 240: 149-167

Fernández-Remolar D C, Chong-Díaz G, Ruíz-Bermejo M, Harir M, Schmitt-Kopplin P, Tziotis D, Gómez-Ortíz D, García-Villadangos M, Martín-Redondo M P, Gómez F, Rodríguez-Manfredi J A, 
Moreno-Paz M, De Diego-Castilla G, Echeverría A, Urtuvia V N, Blanco Y, Rivas L, Izawa M R M, Banerjee N R, Demergasso C, Parro V. 2013. Molecular preservation in halite- and perchloraterich hypersaline subsurface deposits in the Salar Grande basin (Atacama Desert, Chile): Implications for the search for molecular biomarkers on Mars. J Geophys Res-Biogeosci, 118: 922-939

Fernandez A B, Rasuk M C, Visscher P T, Contreras M, Novoa F, Poire D G, Patterson M M, Ventosa A, Farias M E. 2016. Microbial diversity in sediment ecosystems (evaporites domes, microbial mats, and crusts) of hypersaline Laguna Tebenquiche, Salar de Atacama, Chile. Front Microbiol, 7: 1284

Georgiou C D, Deamer D W. 2014. Lipids as universal biomarkers of extraterrestrial life. Astrobiology, 14: 541-549

Georgiou C D, Sun H J, McKay C P, Grintzalis K, Papapostolou I, Zisimopoulos D, Panagiotidis K, Zhang G, Koutsopoulou E, Christidis G E, Margiolaki I. 2015. Evidence for photochemical production of reactive oxygen species in desert soils. Nat Commun, 6: 7100

Gharaibeh A A, Voorhees K J. 1996. Characterization of lipid fatty acids in whole-cell microorganisms using in situ supercritical fluid derivatization/extraction and gas chromatography/mass spectrometry. Anal Chem, 68: 2805-2810

Gong C, Hollander D J. 1997. Differential contribution of bacteria to sedimentary organic matter in oxic and anoxic environments, Santa Monica Basin, California. Org Geochem, 26: 545-563

Grotzinger J P, Arvidson R E, Bell Iii J F, Calvin W, Clark B C, Fike D A, Golombek M, Greeley R, Haldemann A, Herkenhoff K E, Jolliff B L, Knoll A H, Malin M, McLennan S M, Parker T, Soderblom L, Sohl-Dickstein J N, Squyres S W, Tosca N J, Watters W A. 2005. Stratigraphy and sedimentology of a dry to wet eolian depositional system, Burns formation, Meridiani Planum, Mars. Earth Planet Sci Lett, 240: 11-72

Grotzinger J P, Sumner D Y, Kah L C, Stack K, Gupta S, Edgar L, Rubin D, Lewis K, Schieber J, Mangold N, Milliken R, Conrad P G, DesMarais D, Farmer J, Siebach K, Calef F, Hurowitz J, McLennan S M, Ming D, Vaniman D, Crisp J, Vasavada A, Edgett K S, Malin M, Blake D, Gellert R, Mahaffy P, Wiens R C, Maurice S, Grant J A, Wilson S, Anderson R C, Beegle L, Arvidson R, Hallet B, Sletten R S, Rice M, Bell J, Griffes J, Ehlmann B, Anderson R B, Bristow T F, Dietrich W E, Dromart G, Eigenbrode J, Fraeman A, Hardgrove C, Herkenhoff K, Jandura L, Kocurek G, Lee S, Leshin L A, Leveille R, Limonadi D, Maki J, McCloskey S, Meyer M, Minitti M, Newsom H, Oehler D, Okon A, Palucis M, Parker T, Rowland S, Schmidt M, Squyres S, Steele A, Stolper E, Summons R, Treiman A, Williams R, Yingst A, Team M S, Kemppinen O, Bridges N, Johnson J R, Cremers D, Godber A, Wadhwa M, Wellington D,
McEwan I, Newman C, Richardson M, Charpentier A, Peret L, King P, Blank J, Weigle G, Li S, Robertson K, Sun V, Baker M, Edwards C, Farley K, Miller H, Newcombe M, Pilorget C, Brunet C, Hipkin V, Leveille R, Marchand G, Sanchez P S, Favot L, Cody G, Fluckiger L, Lees D, Nefian A, Martin M, Gailhanou M, Westall F, Israel G, Agard C, Baroukh J, Donny C, Gaboriaud A, Guillemot P, Lafaille V, Lorigny E, Paillet A, Perez R, Saccoccio M, Yana C, Armiens-Aparicio C, Rodriguez J C, Blazquez I C, Gomez F G, Gomez-Elvira J, Hettrich S, Malvitte A L, Jimenez M M, MartinezFrias J, Martin-Soler J, Martin-Torres F J, Jurado A M, MoraSotomayor L, Caro G M, Lopez S N, Peinado-Gonzalez V, PlaGarcia J, Manfredi J A R, Romeral-Planello J J, Fuentes S A S, Martinez E S, Redondo J T, Urqui-O'Callaghan R, Mier M P Z, Chipera S, Lacour J L, Mauchien P, Sirven J B, Manning H, Fairen A, Hayes A, Joseph J, Sullivan R, Thomas P, Dupont A, Lundberg A, Melikechi N, Mezzacappa A, DeMarines J, Grinspoon D, Reitz G, Prats B, Atlaskin E, Genzer M, Harri A M, Haukka H, Kahanpaa H, Kauhanen J, Paton M, Polkko J, Schmidt W, Siili T, Fabre C, Wray J, Wilhelm M B, Poitrasson F, Patel K, Gorevan S, Indyk S, Paulsen G, Bish D, Gondet B, Langevin Y, Geffroy C, Baratoux D, Berger G, Cros A, d'Uston C, Forni O, Gasnault O, Lasue J, Lee Q M, Meslin P Y, Pallier E, Parot Y, Pinet P, Schroder S, Toplis M, Lewin E, Brunner W, Heydari E, Achilles C, Sutter B, Cabane M, Coscia D, Szopa C, Robert F, Sautter V, Le Mouelic S, Nachon M, Buch A, Stalport F, Coll P, Francois P, Raulin F, Teinturier S, Cameron J, Clegg S, Cousin A, DeLapp D, Dingler R, Jackson R S, Johnstone S, Lanza N, Little C, Nelson T, Williams R B, Jones A, Kirkland L, Baker B, Cantor B, Caplinger M, Davis S, Duston B, Fay D, Harker D, Herrera P, Jensen E, Kennedy M R, Krezoski G, Krysak D, Lipkaman L, McCartney E, McNair S, Nixon B, Posiolova L, Ravine M, Salamon A, Saper L, Stoiber K, Supulver K, Van Beek J, Van Beek T, Zimdar R, French K L, Iagnemma K, Miller K, Goesmann F, Goetz W, Hviid S, Johnson M, Lefavor M, Lyness E, Breves E, Dyar M D, Fassett C, Edwards L, Haberle R, Hoehler T, Hollingsworth J, Kahre M, Keely L, McKay C, Bleacher L, Brinckerhoff W, Choi D, Dworkin J P, Floyd M, Freissinet C, Garvin J, Glavin D, Harpold D, Martin D K, McAdam A, Pavlov A, Raaen E, Smith M D, Stern J, Tan F, Trainer M, Posner A, Voytek M, Aubrey A, Behar A, Blaney D, Brinza D, Christensen L, DeFlores L, Feldman J, Feldman S, Flesch G, Jun I, Keymeulen D, Mischna M, Morookian J M, Pavri B, Schoppers M, Sengstacken A, Simmonds J J, Spanovich N, Juarez M T, Webster C R, Yen A, Archer P D, Cucinotta F, Jones J H, Morris R V, Niles P, Rampe E, Nolan T, Fisk M, Radziemski L, Barraclough B, Bender S, Berman D, Dobrea E N, Tokar R, Cleghorn T, Huntress W, Manhes G, Hudgins J, Olson T, Stewart N, Sarrazin P, Vicenzi E, Bullock M, 
Ehresmann B, Hamilton V, Hassler D, Peterson J, Rafkin S, Zeitlin C, Fedosov F, Golovin D, Karpushkina N, Kozyrev A, Litvak M, Malakhov A, Mitrofanov I, Mokrousov M, Nikiforov S, Prokhorov V, Sanin A, Tretyakov V, Varenikov A, Vostrukhin A, Kuzmin R, Clark B, Wolff M, Botta O, Drake D, Bean K, Lemmon M, Schwenzer S P, Lee E M, Sucharski R, Hernandez M A P, Avalos J J B, Ramos M, Kim M H, Malespin C, Plante I, Muller J P, NavarroGonzalez R, Ewing R, Boynton W, Downs R, Fitzgibbon M, Harshman K, Morrison S, Kortmann O, Williams A, Lugmair G, Wilson M A, Jakosky B, Balic-Zunic T, Frydenvang J, Jensen J K, Kinch K, Koefoed A, Madsen M B, Stipp S L S, Boyd N, Campbell J L, Perrett G, Pradler I, VanBommel S, Jacob S, Owen T, Savijarvi H, Boehm E, Bottcher S, Burmeister S, Guo J, Kohler J, Garcia C M, Mueller-Mellin R, Wimmer-Schweingruber R, Bridges J C, McConnochie T, Benna M, Franz H, Bower H, Brunner A, Blau H, Boucher T, Carmosino M, Atreya S, Elliott H, Halleaux D, Renno N, Wong M, Pepin R, Elliott B, Spray J, Thompson L, Gordon S, Ollila A, Williams J, Vasconcelos P, Bentz J, Nealson K, Popa R, Moersch J, Tate C, Day M, Francis R, McCullough E, Cloutis E, ten Kate I L, Scholes D, Slavney S, Stein T, Ward J, Berger J, Moores J E. 2014. A habitable fluvio-lacustrine environment at Yellowknife Bay, Gale crater, Mars. Science, 343: 1242777

Hamilton C W, Mouginis-Mark P J, Sori M M, Scheidt S P, Bramson A M. 2018. Episodes of aqueous flooding and effusive volcanism associated with Hrad Vallis, Mars. J Geophys Res-Planets, 123: $1484-1510$

Horgan B H N, Anderson R B, Dromart G, Amador E S, Rice M S. 2020. The mineral diversity of Jezero crater: Evidence for possible lacustrine carbonates on Mars. Icarus, 339: 113526

Jiang H C, Dong H L, Zhang G X, Yu B S, Chapman L R, Fields M W. 2006. Microbial diversity in water and sediment of Lake Chaka, an athalassohaline lake in northwestern China. Appl Environ Microbiol, 72: 3832-3845

Jones C M. 2011. Reconstruction of microbial and environmental conditions in an Australian hypersaline ecosystem from the midPleistocene through the present. Dissertation for Doctoral Degree. Berkeley: University of California

Kaneda T. 1991. Iso- and anteiso-fatty acids in bacteria: Biosynthesis, function, and taxonomic significance. Microbiol Rev, 55: 288-302

Karunatillake S, Keller J M, Squyres S W, Boynton W V, Brückner J, Janes D M, Gasnault O, Newsom H E. 2007. Chemical compositions at Mars landing sites subject to Mars Odyssey Gamma Ray Spectrometer constraints. J Geophys Res, 112: E08S90

Kerber L, Dickson J L, Head J W, Grosfils E B. 2017. Polygonal ridge networks on Mars: Diversity of morphologies and the special case of the Eastern Medusae Fossae Formation. Icarus, 281: 200-219
Kronyak R E, Kah L C, Edgett K S, VanBommel S J, Thompson L M, Wiens R C, Sun V Z, Nachon M. 2019. Mineral-filled fractures as indicators of multigenerational fluid flow in the Pahrump Hills member of the Murray formation, Gale crater, Mars. Earth Space Sci, 6: 238-265

Klenner F, Postberg F, Hillier J, Khawaja N, Reviol R, Stolz F, Cable M L, Abel B, Nölle L. 2020. Analog experiments for the identification of trace biosignatures in ice grains from extraterrestrial ocean worlds. Astrobiology, 20: 179-189

Kong F J, Zheng M P, Hu B, Wang A L, Ma N N, Sobron P. 2018. Dalangtan Saline Playa in a hyperarid region on Tibet Plateau: I. Evolution and environments. Astrobiology, 18: 1243-1253

Niemann H, Elvert M. 2008. Diagnostic lipid biomarker and stable carbon isotope signatures of microbial communities mediating the anaerobic oxidation of methane with sulphate. Org Geochem, 39: 1668-1677

Osterloo M M, Hamilton V E, Bandfield J L, Glotch T D, Baldridge A M, Christensen P R, Tornabene L L, Anderson F S. 2008. Chloridebearing materials in the southern highlands of Mars. Science, 319 : 1651-1654

Pavlov A A, Vasilyev G, Ostryakov V M, Pavlov A K, Mahaffy P. 2012. Degradation of the organic molecules in the shallow subsurface of Mars due to irradiation by cosmic rays. Geophys Res Lett, 39: L13202

Pancost R D, Hopmans E C, Sinninghe Damsté J S. 2001. Archaeal lipids in Mediterranean cold seeps: Molecular proxies for anaerobic methane oxidation. Geochim Cosmochim Acta, 65: 1611-1627

Rasuk M C, Kurth D, Flores M R, Contreras M, Novoa F, Poire D, Farias M E. 2014. Microbial characterization of microbial ecosystems associated to evaporites domes of gypsum in Salar de Llamara in Atacama Desert. Microb Ecol, 68: 483-494

Rütters H, Sass H, Cypionka H, Rullkötter J. 2002. Phospholipid analysis as a tool to study complex microbial communities in marine sediments. J Microbiol Methods, 48: 149-160

Sánchez-García L, Aeppli C, Parro V, Fernández-Remolar D, GarcíaVilladangos M, Chong-Diaz G, Blanco Y, Carrizo D. 2018. Molecular biomarkers in the subsurface of the Salar Grande (Atacama, Chile) evaporitic deposits. Biogeochemistry, 140: 31-52

Schouten S, Hopmans E C, Sinninghe Damsté J S. 2013. The organic geochemistry of glycerol dialkyl glycerol tetraether lipids: A review. Org Geochem, 54: 19-61

Schouten S, Van Der Maarel M J E C, Huber R, Damste J S S. 1997. 2,6,10,15,19-Pentamethylicosenes in Methanolobus bombayensis, a marine methanogenic archaeon, and in Methanosarcina mazei. Org Geochem, 26: 409-414

Schubert B A, Lowenstein T K, Timofeeff M N, Parker M A. 2010. 
Halophilic Archaea cultured from ancient halite, Death Valley, California. Environ Microbiol, 12: 440-454

Stiehl T, Rullkötter J, Nissenbaum A. 2005. Molecular and isotopic characterization of lipids in cultured halophilic microorganisms from the Dead Sea and comparison with the sediment record of this hypersaline lake. Org Geochem, 36: 1242-1251

Tan J, Lewis J M T, Sephton M A. 2018. The fate of lipid biosignatures in a Mars-analogue sulfur stream. Sci Rep, 8: 7586

Tanaka K L, Robbins S J, Fortezzo C M, Skinner Jr. J A, Hare T M. 2014. The digital global geologic map of Mars: Chronostratigraphic ages, topographic and crater morphologic characteristics, and updated resurfacing history. Planet Space Sci, 95: 11-24

Tarnas J D, Mustard J F, Lin H, Goudge T A, Amador E S, Bramble M S, Kremer C H, Zhang X, Itoh Y, Parente M. 2019. Orbital identification of hydrated silica in Jezero Crater, Mars. Geophys Res Lett, 46: 12771-12782

Turich C, Freeman K H. 2011. Archaeal lipids record paleosalinity in hypersaline systems. Org Geochem, 42: 1147-1157

Vaniman D T, Bish D L, Ming D W, Bristow T F, Morris R V, Blake D F, Chipera S J, Morrison S M, Treiman A H, Rampe E B, Rice M, Achilles C N, Grotzinger J P, McLennan S M, Williams J, Bell J F, Newsom H E, Downs R T, Maurice S, Sarrazin P, Yen A S, Morookian J M, Farmer J D, Stack K, Milliken R E, Ehlmann B L, Sumner D Y, Berger G, Crisp J A, Hurowitz J A, Anderson R, Des Marais D J, Stolper E M, Edgett K S, Gupta S, Spanovich N, Agard C, Alves Verdasca J A, Anderson R, Archer D, Armiens-Aparicio C, Arvidson R, Atlaskin E, Atreya S, Aubrey A, Baker B, Baker M, Balic-Zunic T, Baratoux D, Baroukh J, Barraclough B, Bean K, Beegle L, Behar A, Bender S, Benna M, Bentz J, Berger J, Berman D, Blanco Avalos J J, Blaney D, Blank J, Blau H, Bleacher L, Boehm E, Botta O, Bottcher S, Boucher T, Bower H, Boyd N, Boynton B, Breves E, Bridges J, Bridges N, Brinckerhoff W, Brinza D, Brunet C, Brunner A, Brunner W, Buch A, Bullock M, Burmeister S, Cabane M, Calef F, Cameron J, Campbell J I, Cantor B, Caplinger M, Caride Rodriguez J, Carmosino M, Carrasco Blazquez I, Charpentier A, Choi D, Clark B, Clegg S, Cleghorn T, Cloutis E, Cody G, Coll P, Conrad P, Coscia D, Cousin A, Cremers D, Cros A, Cucinotta F, d'Uston C, Davis S, Day M K, de la Torre Juarez M, DeFlores L, DeLapp D, DeMarines J, Dietrich W, Dingler R, Donny C, Drake D, Dromart G, Dupont A, Duston B, Dworkin J, Dyar M D, Edgar L, Edwards C, Edwards L, Ehresmann B, Eigenbrode J, Elliott B, Elliott H, Ewing R, Fabre C, Fairen A, Farley K, Fassett C, Favot L, Fay D, Fedosov F, Feldman J, Feldman S, Fisk M, Fitzgibbon M, Flesch G, Floyd M, Fluckiger L, Forni O, Fraeman A, Francis R, Francois P, Franz H, Freissinet C, French K L, Frydenvang J, Gaboriaud A, Gailhanou M, Garvin J,
Gasnault O, Geffroy C, Gellert R, Genzer M, Glavin D, Godber A, Goesmann F, Goetz W, Golovin D, Gomez Gomez F, Gomez-Elvira J, Gondet B, Gordon S, Gorevan S, Grant J, Griffes J, Grinspoon D, Guillemot P, Guo J, Guzewich S, Haberle R, Halleaux D, Hallet B, Hamilton V, Hardgrove C, Harker D, Harpold D, Harri A M, Harshman K, Hassler D, Haukka H, Hayes A, Herkenhoff K, Herrera P, Hettrich S, Heydari E, Hipkin V, Hoehler T, Hollingsworth J, Hudgins J, Huntress W, Hviid S, Iagnemma K, Indyk S, Israel G, Jackson R, Jacob S, Jakosky B, Jensen E, Jensen J K, Johnson J, Johnson M, Johnstone S, Jones A, Jones J, Joseph J, Jun I, Kah L, Kahanpaa H, Kahre M, Karpushkina N, Kasprzak W, Kauhanen J, Keely L, Kemppinen O, Keymeulen D, Kim M H, Kinch K, King P, Kirkland L, Kocurek G, Koefoed A, Kohler J, Kortmann O, Kozyrev A, Krezoski J, Krysak D, Kuzmin R, Lacour J L, Lafaille V, Langevin Y, Lanza N, Lasue J, Le Mouelic S, Lee E M, Lee Q M, Lees D, Lefavor M, Lemmon M, Malvitte A L, Leshin L, Leveille R, Lewin-Carpintier E, Lewis K, Li S, Lipkaman L, Little C, Litvak M, Lorigny E, Lugmair G, Lundberg A, Lyness E, Madsen M, Mahaffy P, Maki J, Malakhov A, Malespin C, Malin M, Mangold N, Manhes G, Manning H, Marchand G, Marin Jimenez M, Martin Garcia C, Martin D, Martin M, Martinez-Frias J, MartinSoler J, Martin-Torres F J, Mauchien P, McAdam A, McCartney E, McConnochie T, McCullough E, McEwan I, McKay C, McNair S, Melikechi N, Meslin P Y, Meyer M, Mezzacappa A, Miller H, Miller K, Minitti M, Mischna M, Mitrofanov I, Moersch J, Mokrousov M, Molina Jurado A, Moores J, Mora-Sotomayor L, Mueller-Mellin R, Muller J P, Munoz Caro G, Nachon M, Navarro Lopez S, Navarro-Gonzalez R, Nealson K, Nefian A, Nelson T, Newcombe M, Newman C, Nikiforov S, Niles P, Nixon B, Noe Dobrea E, Nolan T, Oehler D, Ollila A, Olson T, Owen T, de Pablo Hernandez M A, Paillet A, Pallier E, Palucis M, Parker T, Parot Y, Patel K, Paton M, Paulsen G, Pavlov A, Pavri B, Peinado-Gonzalez V, Pepin R, Peret L, Perez R, Perrett G, Peterson J, Pilorget C, Pinet P, Pla-Garcia J, Plante I, Poitrasson F, Polkko J, Popa R, Posiolova L, Posner A, Pradler I, Prats B, Prokhorov V, Purdy S W, Raaen E, Radziemski L, Rafkin S, Ramos M, Raulin F, Ravine M, Reitz G, Renno N, Richardson M, Robert F, Robertson K, Rodriguez Manfredi J A, Romeral-Planello J J, Rowland S, Rubin D, Saccoccio M, Salamon A, Sandoval J, Sanin A, Sans Fuentes S A, Saper L, Sautter V, Savijarvi H, Schieber J, Schmidt M, Schmidt W, Scholes D D, Schoppers M, Schroder S, Schwenzer S, Sebastian Martinez E, Sengstacken A, Shterts R, Siebach K, Siili T, Simmonds J, Sirven J B, Slavney S, Sletten R, Smith M, Sobron Sanchez P, Spray J, Squyres S, Stalport F, Steele A, Stein T, Stern J, Stewart N, Stipp S L S, Stoiber K, Sucharski B, Sullivan R, Summons R, Sun V, Supulver K, Sutter B, Szopa C, Tan F, Tate C, Teinturier S, ten Kate 
I, Thomas P, Thompson L, Tokar R, Toplis M, Torres Redondo J, Trainer M, Tretyakov V, Urqui-O'Callaghan R, Van Beek J, Van Beek T, VanBommel S, Varenikov A, Vasavada A, Vasconcelos P, Vicenzi E, Vostrukhin A, Voytek M, Wadhwa M, Ward J, Webster C, Weigle E, Wellington D, Westall F, Wiens R C, Wilhelm M B, Williams A, Williams R, Williams R B M, Wilson M, WimmerSchweingruber R, Wolff M, Wong M, Wray J, Wu M, Yana C, Yingst A, Zeitlin C, Zimdar R, Zorzano Mier M P. 2014. Mineralogy of a mudstone at Yellowknife Bay, Gale crater, Mars. Science, 343: 1243480

Wang A L, Sobron P, Kong F J, Zheng M P, Zhao Y Y S. 2018. Dalangtan saline playa in a hyperarid region on Tibet Plateau-II: Preservation of salts with high hydration degrees in subsurface. Astrobiology, 18: 1254-1276

Westall F, Foucher F, Bost N, Bertrand M, Loizeau D, Vago J L, Kminek G, Gaboyer F, Campbell K A, Bréhéret J G, Gautret P, Cockell C S. 2015. Biosignatures on Mars: What, where, and how? Implications for the search for Martian life. Astrobiology, 15: 998-
1029

Wilhelm M B, Davila A F, Eigenbrode J L, Parenteau M N, Jahnke L L, Liu X L, Summons R E, Wray J J, Stamos B N, O'Reilly S S, Williams A. 2017. Xeropreservation of functionalized lipid biomarkers in hyperarid soils in the Atacama Desert. Org Geochem, 103: $97-104$

Williams A J, Craft K L, Millan M, Johnson S S, Knudson C A, Juarez Rivera M, McAdam A C, Tobler D, Skok J R. 2021. Fatty acid preservation in modern and relict hot-spring deposits in Iceland, with implications for organics detection on Mars. Astrobiology, 21: $60-82$

Xiao L, Wang J, Dang Y N, Cheng Z Y, Huang T, Zhao J N, Xu Y, Huang J, Xiao Z Y, Komatsu G. 2016. A new terrestrial analogue site for Mars research: The Qaidam Basin, Tibetan Plateau (NW China). Earth-Sci Rev, 164: 84-101

Xie S C, Chen F H, Wang Z Y, Wang H M, Gu Y S, Huang Y S. 2003. Lipid distributions in loess-paleosol sequences from northwest China. Org Geochem, 34: 1071-1079

(责任编委: 张传伦) 